\title{
Evolutionary Characteristics of Project Interdependent Network within National Quality Award Projects of China
}

\author{
Lixin $\mathrm{Fu}^{1, \mathrm{a}}$, Liang $\operatorname{Liu}^{2 *}$, \\ ${ }^{1}$ School of Management, Shanghai University Shanghai 200444, China \\ ${ }^{2}$ School of Management, Shanghai University Shanghai 200444, China
}

\begin{abstract}
The research on the evolutionary law of project interdependent network is the innovation in construction industry. Based on the complex network theory and method, this research establishes the projectproject correlation network, and it is built based on the actual case of the National Quality Award Projects of China (NQAPC). We aim to systematically analyze the structural characteristics and evolution mechanism of the project interdependent network by using global network parameters. As network size increases, the degree follows power-law distribution, the average path length tends to decrease, and the clustering coefficient and heterogeneity gradually increases. The research results may help managers achieve higher performance in strategic network management of construction projects.
\end{abstract}

\section{Introduction}

As an extension of the project concept, the project program is a group of interrelated projects that need to be coordinated and managed 1 . The project program is a strategic community composed of several different subprojects according to a specific structure. There are temporal, geographical or logical interrelationships between the projects 2. In addition, during the implementation of the project program, there are uncertainties such as fierce resource conflicts, the changing industry environment and target constraints 3 . Thereby, the effective management of the project program needs to be based on complex thinking and theory, from a strategic height, in order to obtain the overall goal of the project program and the emergence of organizational functions.

Traditionally, the standard for measuring the success of a project is to "complete the project on time, within budget and within prescribed standards", but it is far from enough to measure the success of the project program. The project program management has complex interface, long implementation cycle, large capital investment, heavy workload of organizational coordination, and strong interaction with external environment. Therefore, managing large-scale project program by using traditional project management knowledge system and tools has induced several problems such as loss of control of goals, delayed decision-making, low organizational efficiency, unbalanced resources, and information asymmetry 4 . How to better control the project status and process, and coordinate the organization's interests and conflicts has become an urgent problem to be solved. After reviewing the previous research literature, Mark et al. put forward that project program managers should explore the management methods that adapt to the specific characteristics of the project program, such as culture, political environment and organizational challenges, from a strategic perspective 5. Partington et al. divided the competitiveness of the project program management into four levels, and constructed an analysis framework for competitiveness of project program management 6 .

The interdependence of multiple projects in the project program forms an intricately correlated system 7. Complex network is an abstraction of complex system, and it can effectively describe the topological structure of complex system, revealing the hidden laws of complex system from the structural point of view 8 . At present, the research on the relationship structure of project-project correlation network has been widely carried out in the fields of finance, technology, innovation, and R\&D projects. For example, Zaabi used several social network system indicators to analyze the interdependence of projects based on the network and node levels 9. Pardis et al. used network analysis methods to better understand the relationship and interdependence between basic fasttracking practices in the construction industry 10 . In general, the specific research on this aspect of the construction industry is still in the exploratory stage. There is a lack of consideration of the interdependence of large-scale engineering projects at the national or industry level, and the research on the related network structure and evolution of the project program is even rarer.

To address this research gap, based on the case of the National Quality Award Projects of China (NQAPC), this research builds a project-project correlation network based on organization associations, and uses global network parameters to systematically analyze the structural characteristics and evolution mechanism of the

ae-mail: flx_naughty@163.com

b* Corresponding author: e-mail: liangliu@shu.edu.cn 
project interdependent network. The innovations of this study are: we transform the traditional dichotomous network from the organization projection to the project projection, and propose to shift from the interorganizational network based on project cooperation to the inter-project network based on organizational relationships. We use complex network methods to the indepth identification of the project network evolution characteristics at the national level. The research results may help managers to achieve higher performance of strategic network management in construction project management.

\section{Basic network analysis parameters}

To analyze the topology properties of the NQAPC project interdependent network, we use seven selected networklevel global measurement parameters, namely density, diameter, average degree, degree distribution, heterogeneity, clustering coefficient and average path length etc. The theoretical definition and practical significance of all selected parameters are summarized in Table 1.

TABLE I. Theoretical definition and practical significance of network-level parameters

\begin{tabular}{|c|c|c|}
\hline Name & Theoretical definition & Practical significance \\
\hline Density & $\begin{array}{l}\text { The ratio of actual connections in the network to the maximum } \\
\text { number of possible connections }\end{array}$ & $\begin{array}{l}\text { A higher density represents a higher project relevance of the } \\
\text { network, and the network has a stronger cohesion. }\end{array}$ \\
\hline Diameter & $\begin{array}{l}\text { The maximum value of the geodesic distance between all pairs } \\
\text { of nodes in the network }\end{array}$ & $\begin{array}{l}\text { The larger the diameter, the more difficult the communication } \\
\text { between these projects. }\end{array}$ \\
\hline $\begin{array}{l}\text { Average } \\
\text { degree }\end{array}$ & The average degree of all nodes in the network & $\begin{array}{l}\text { The higher the average degree, the larger the scale of the network } \\
\text { and the closer the network connection. }\end{array}$ \\
\hline $\begin{array}{l}\text { Degree } \\
\text { distribution }\end{array}$ & $\begin{array}{l}\text { node degree distribution function } \mathrm{P}(\mathrm{k}) \text { or cumulative degree } \\
\text { distribution function } \mathrm{P}(>\mathrm{k})\end{array}$ & $\begin{array}{c}\text { The degree distribution of the project program network represents } \\
\text { the probability that a randomly selected project has k directly } \\
\text { correlated. }\end{array}$ \\
\hline $\begin{array}{l}\text { Heterogeneit } \\
\qquad y\end{array}$ & $\begin{array}{l}\text { A measure of the degree of uniformity of node distribution (in } \\
\text { undirected networks, the degree of heterogeneity of regular } \\
\text { networks is } 0 \text {; in scale-free networks, the degree of } \\
\text { heterogeneity is higher than regular network) }\end{array}$ & $\begin{array}{l}\text { Reflecting certain tendency and disorder of the network structure } \\
\text { caused by the uneven distribution of project characteristics, the } \\
\text { greater the degree of network heterogeneity, the more complicated } \\
\text { the connection of each project in the network. }\end{array}$ \\
\hline $\begin{array}{l}\text { Average } \\
\text { clustering } \\
\text { coefficient }\end{array}$ & $\begin{array}{l}\text { The average clustering coefficient of the network is the } \\
\text { average of the clustering coefficients of all nodes }\end{array}$ & $\begin{array}{l}\text { Explain the professional distance between different projects, the } \\
\text { homology of contractors, and the transferability of cooperation } \\
\text { between common contractors among projects, etc. }\end{array}$ \\
\hline $\begin{array}{l}\text { Average path } \\
\text { length }\end{array}$ & $\begin{array}{l}\text { The average of the shortest path length of all nodes in the } \\
\text { network }\end{array}$ & $\begin{array}{l}\text { The smaller the average path length, the easier the information } \\
\text { transmission between the projects. }\end{array}$ \\
\hline
\end{tabular}

\section{A case study of the NQAPC network}

\subsection{The NQAPC network model}

In the construction industry of China, the scale of engineering projects is increasing, involving more technical fields and wider geographical range. Such megaproject program needs to be completed by a large number of contractors with various professional qualifications and technical advantages. As a part of the Chinese Quality Product Award, the National Quality Projects Award is the highest honor award in terms of construction quality (http://www.cacem.com.cn/), as well as the earliest national quality award with the highest specification requirements in the construction industry in China. The National Quality Project Award covers 10 types of projects, including housing construction, municipal engineering, railway, highway, electric power, chemical engineering, smelting, port, water conservancy and communications, and the award targets include project enterprises in construction, design and consulting. Since its establishment in 1981, 1410 engineering projects have been awarded successively, among which 50 have won the gold medal and 1360 have won the silver medal, representing the highest level of project quality in the construction industry of China.
This study takes the project interdependent network of NQAPC as the case. Considering the authority and completeness of published data, a bipartite network is firstly established based on the awarded projects and the contractors from 2003 to 2012 . Fig. 1 shows a schematic view for explaining the bipartite network and its projection. The upper nodes are regarded as the contractor organizations, while the lower nodes are the award winning projects. Then, based on the complex network modeling and analysis method, this research build the cumulative largest interconnected cluster topology of the NQAPC network from 2003 to 2012 by using Cytoscape software, as is shown in Fig. 2, giving us a good understanding of the evolution of the range and configuration of the networks over time.

Table 2 shows the statistical data of the overall NQAPC network from 2003 to 2012. Statistics show that the NQAPC network as of 2012 contains 1,307 awardwinning projects and 948 contractors. With the increase of the project interdependent network, the proportion of projects within the largest component to the total number of projects increases rapidly, from $7.41 \%$ in 2003 to $82.1 \%$ in 2012. The number of project interconnections within the largest component, $\mathrm{M}$ (i.e., the number of network edges), from less than ten to tens of thousands, indicating that the number of contractors shared by different projects through organizational association (technical cooperation or resource sharing) is increasing, and the project 
correlations become more common. This study mainly analyzes the largest component of the NQAPC network from 2003 to 2012. This is for two reasons: On the one hand, the largest component contains at least $80 \%$ of the projects in the whole network, which can accurately express the interconnection mode and basic characteristics of the NQAPC network. On the other hand, it can avoid the calculation error of network global parameters caused by the existence of a few isolated nodes or small connected component.

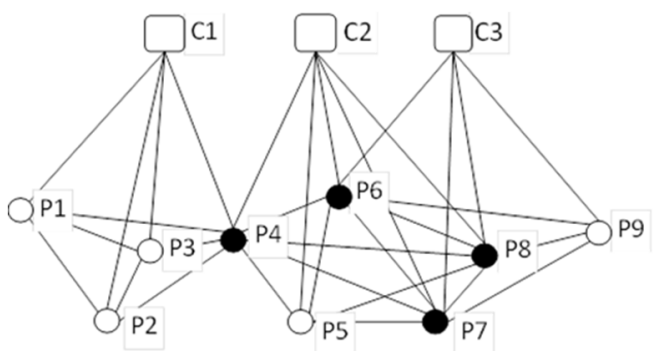

Figure 1. Schematic view for explaining bipartite graph and its projection

\subsection{Structural evolution analysis of the NQAPC network}

In this section, we will explore the structural evolution of the NQAPC network. In particular, we use the seven network-level global measurement parameters selected in Table 1 to characterize the structural evolution of the largest component. And based on the network characteristics, we discuss how to cultivate a strong and effective construction mode of project program network to help us understand the project interdependent network more deeply and comprehensively. Since the largest component in 2003 is quite small, the global measurement of the connection network in 2003 is meaningless, therefore, it is excluded.

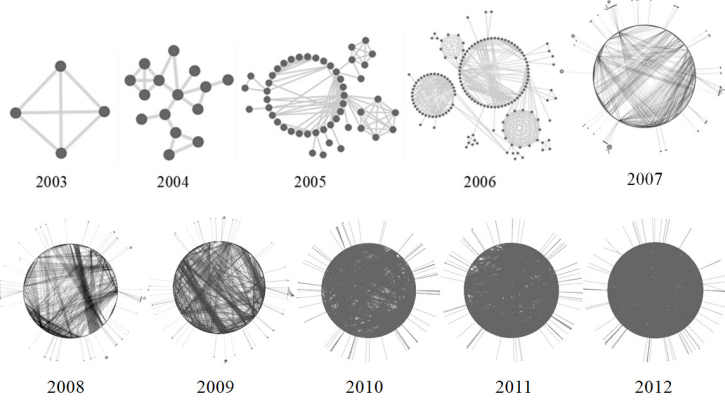

Figure 2. The cumulative largest interconnected cluster topology of the NQAPC network (2003-2012)

Table II. Total network statistics of the NQAPC from 2003 to 2012

\begin{tabular}{|c|c|c|c|c|c|c|c|c|c|c|}
\hline Year & 2003 & 2004 & 2005 & 2006 & 2007 & 2008 & 2009 & 2010 & 2011 & 2012 \\
\hline Statistical characteristic & 54 & 74 & 86 & 116 & 155 & 138 & 149 & 145 & 191 & 199 \\
\hline number of projects each year & 91 & 142 & 158 & 201 & 237 & 210 & 296 & 273 & 333 & 281 \\
\hline number of contractors each year & 54 & 128 & 214 & 330 & 485 & 623 & 772 & 917 & 1108 & 1307 \\
\hline number of projects up to year & 91 & 207 & 296 & 400 & 500 & 590 & 680 & 767 & 863 & 948 \\
\hline $\begin{array}{c}\text { Number of contractors up to year } \\
\text { number of nodes (projects) in the largest component up } \\
\text { to year }\end{array}$ & 4 & 15 & 49 & 152 & 336 & 465 & 587 & 731 & 905 & 1073 \\
\hline $\begin{array}{c}\text { number of nodes (projects) in the largest component up } \\
\text { to year(as a percentage \%) }\end{array}$ & 7.41 & 11.72 & 22.9 & 46.06 & 69.28 & 74.64 & 76.04 & 79.72 & 81.68 & 82.10 \\
\hline $\begin{array}{c}\text { number of edges (interconnections) in the largest } \\
\text { component up to year }\end{array}$ & 6 & 20 & 131 & 560 & 1606 & 2848 & 4262 & 6024 & 8251 & 11563 \\
\hline
\end{tabular}

\subsubsection{Density decreases and diameter fluctuates}

Fig. 3 shows the evolution of the density and diameter of the NQAPC network over the years from 2003 to 2012. It can be seen from Fig. 3a, that as the scale of the project interdependent network increases, the overall network density decreases sharply from 0.19 (2004) to 0.02 (2012), and the network becomes more and more sparse. This indicates many newly added projects only share a few contractors with part of the original projects in the network. This is consistent with the actual phenomenon. Because the size of a project is limited, it only needs to work with part of the contractors who can complete the project. At the same time, these contractors are involved in the construction of other projects. Through the connection of these contractors with the existing projects, the new projects are embedded in the network. Fig. 3b shows that as the scale of the network increases, the network diameter experiences fluctuations in the first few years, and finally stabilizes at 9 (we set the distance between two adjacent projects to 1). This shows that when the network size increases to a certain extent, any two projects in the network can be established a connection with other projects less than 10 steps, indicating that the NQAPC has greater relevance. And it also shows that the domestic contractor market is very active. Contractors with multiple qualifications have participated in different types of projects, and a few key contractors involved in a large number of projects, forming a bridge between projects, leading to "ten-degree connected spaces." 

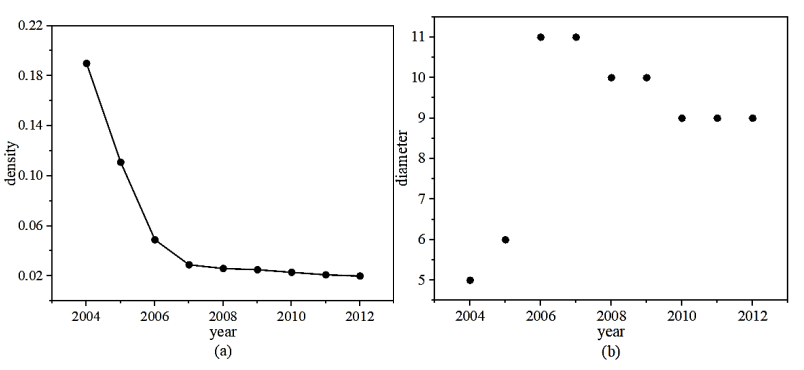

Figure 3. Evolution of the density and diameter of the cumulative largest component up to the given year.

\subsubsection{Average degree and heterogeneity increases with time}

The average degree, that is, the average number of edges (connection) per node (project), can represent the connectivity of the overall network. Fig. 4a shows that as the network scale develops, the average degree of the network increases linearly, and it increases dramatically from an initial value of 2.667 in 2004 to 21.553 in 2012. This indicates that, as time goes by, due to the addition of new projects, the number of nodes increase, and the total edge growth is faster than that of projects. Because the new edges not only come from the connections between the new projects, but also from the connections between the new projects and the existing projects in the network. The number of nodes and edges of the largest component during 2003-2012 shown in Table 2 can confirm this. By 2012, the average degree of the network was 21.553, which means that each project is directly related to more than 21 projects on average. People can say that the connections between NQAPC projects are close.

In the field of complex networks, "network heterogeneity" is regarded as an abstract concept, reflecting a tendency and disorder of the whole network structure, caused by the uneven distribution of nodes. Fig. $4 \mathrm{~b}$ shows that as the scale of the NQAPC network increases, the heterogeneity of the network highlights two distinct time periods: a first term (2004-2008) during which increases sharply from about 0.5 (2004) to 0.9 (2008), and a second term (2009-2012), during which the growth slows down from 0.9 in 2009 to close to 1 in 2012. It indicates that the degree of difference in the characteristics of the network is increasing, and the characteristics of the projects are more scattered. For example, with the continuous improvement of the country's economic, scientific and technological level, the investment in the field of engineering has increased substantially, and the scope gradually covers ten types of engineering majors, including housing construction, municipal engineering, railways, highways, electric power, chemical engineering, smelting, ports, water conservancy and communications. Moreover, different contractors in the NQAPC network have differences in professionalism, qualifications, influence, etc., making the network structure dependent on the bridging of some important nodes. The activity capacity and the level of related projects of the project vary greatly in the network.
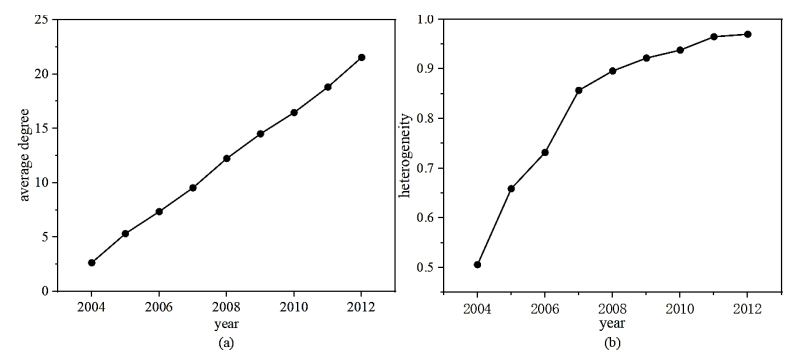

Figure 4. Evolution of the average degree and heterogeneity of the cumulative largest component up to the given year.

\subsubsection{Degree distribution follows the same rule}

A typical widely studied global network attribute is the distribution of node degree. The statistical results show that the degree distribution of many large-scale networks obeys the power-law distribution. Researchers call this kind of network scale-free network 11. The graph of the distribution $\mathrm{P}(k)$ of the number of connection $\mathrm{k}$ for each project is quite rugged, especially at the tail of the distribution. Instead, we use the cumulative form, which can effectively reduce the number of statistical errors caused by the system size, while the shape of the distribution is well preserved 12. Fig. 5 shows that from 2004 to 2012, the NQAPC network presents an approximate degree distribution, and its distribution characteristics are mainly reflected in more nodes with small degree and less nodes with large degree. As shown in Figure 5, the range of degree is between $1 \sim 141$, and there are only 9 nodes with degree more than 100; the number of nodes with degree between $1 \sim 25$ is more than $70 \%$ of the total number of nodes, which indicates that the degree distribution of NQAPC network follows the power-law distribution, and the network has obvious scale-free characteristics.

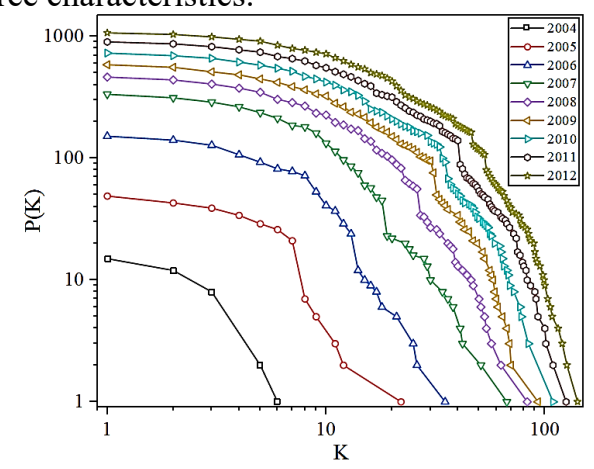

Figure 5. Evolution of the cumulative degree distribution of the largest component up to the given year.

\subsubsection{The clustering coefficient increases while average path length decreases}

The global clustering coefficient of the NQAPC network also shows a steady rising trend, and the value is generally large $(>0.7)$, as is shown in Fig. 6a. This indicates that the larger the scale of the network, the greater the degree of clustering among projects and the more intensive the connection, showing a trend of network collectivization. However, after 2009, the clustering coefficient of the cumulative network decreases slightly, from 0.789 (2008) 
to 0.779 (2012). The possible reason is that most of the newly added projects are relatively small in scale and simple in technology, requiring fewer types and numbers of contractors. These projects share few contractors with very few projects in the network, eventually forming a situation of edge embedding. Moreover, the clustering coefficient in the NQAPC network tells us the extent to which contractors are willing to cooperate with each other. For the project interdependent network after 2006, there is a very strong cluster $\mathrm{C}>0.77$. According to the definition of clustering, a new project continued to be undertaken by a contractor who has participated in at least two projects will be added to the network with a clustering coefficient of 1 , this is also the reason why the network can maintain a high clustering coefficient.

Fig. 6b shows the evolution of the average path length of the NQAPC network. It increases sharply to 4.578 in 2007, during the first term; then it continues to decline during the second term, and finally stays at 3.456 in 2012 . This indicates that the domestic engineering contractor market has experienced a stage, from rapid filling in quantity to continuous development and growth in qualifications. Some core contractors have gradually contracted diversified and complex engineering projects, which has greatly shortened the distance between projects. Overall, the average path length of the project interdependent network is around 3.5, demonstrating that a pair of two projects requires up to four intermediate points to be connected, which will have a profound impact on the operation of the construction community. The small "average path length" between projects allows for the rapid diffusion of new ideas, technologies, and resources among members, in the process of participating in the construction of large-scale projects, which is conducive to contractors to learn from the experience of successful projects, and to improve project performance.
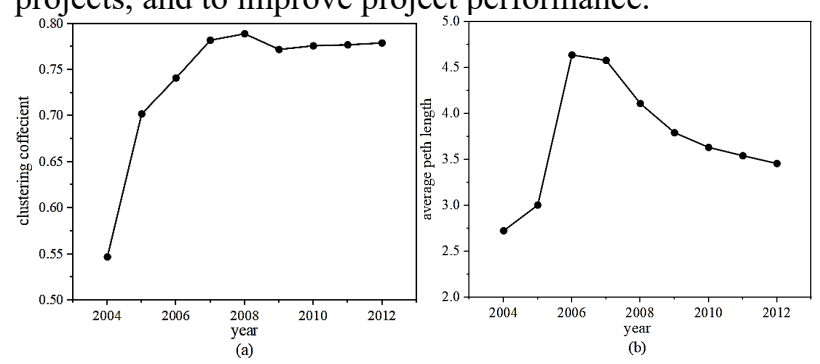

Figure 6. Evolution of the clustering coefficient and average path length of the cumulative largest component up to the given year.

\section{Conclusion}

By means of the network analysis method, we abstract the NQAPC project interdependent network from 2003 to 2012. We mainly focuses on the global structure of the network, and the constructed network is large, containing about 1100 projects, so it is possible to provide reliable statistical descriptions of the structural properties. Some meaningful global network metrics are used to empirically study the structural evolution of these networks. The following are the findings of the survey and their impact on the construction industry by summarizing most of the statistics of the project-project correlation network up to 2012:

- With the development of China's construction industry, the network structure of NQAPC has undergone a structural shift from an unconnected small network to a larger network. In our case, the scale of mega component in 2012 was 1073 award-winning projects, accounting for $82.1 \%$ of the total project network. This means that $82.1 \%$ of the projects in the NQAPC network belong to the same community, and each project in the community is linked to each other through some direct and indirect connections.

- Statistics show that as the scale of the project program becomes larger, the density of the NQAPC network gradually decreases. The average number of direct connections per project increases year by year, as of 2012, the average degree has increased to 21.553 . It shows that the NQAPC network is still growing, the relationship between contractors is getting closer, and the Chinese construction market is currently not in danger of splitting.

- According to complex network theory, the NQAPC network exhibits short average path lengths and high clustering coefficients, such as the average path length finally stabilizes at 3.456 in 2012, and the clustering coefficients is generally higher than 0.77 after 2006, which has obvious small-world characteristics, indicating that within giant component, projects become closely linked through organizational cooperation. At the same time, the degree distribution of the NQAPC network follows the same rule, showing obvious scale-free.

Network analysis method provides a new perspective to deeply understand the evolution characteristics of the construction industry. This research emphasizes the importance of the global network view by analyzing actual connection cases in the construction field. By selecting seven network-level global measurement parameters, this study analyzed the macro-scale structure of the NQAPC network. These interesting findings can help managers to establish the universality of the cognition and social mechanism behind the construction process, and help contractors to better formulate more reasonable cooperation strategies. Our research must take into account some limitations. First of all, due to the limited data samples in China, these findings are not entirely suitable for every country. Secondly, due to data collection channels and huge amount of data, the data has gaps for several years, and it is difficult to reflect the latest situation in a timely manner. In addition, this study only focuses on the evolution of the network topology at the macro-scale. Future research can build a multi-scale analysis framework of project network from motif, module to global level, using the latest time window data to further explore the characteristics and evolution of the project interdependent network in the field of construction based on organizational cooperation. 


\section{Acknowledgment}

This work is supported by the Natural Science Foundation of China (Nos. 71602107 and 71874123), the China Scholarship Council (No. 201806895024), and the Shanghai Leading Academic Discipline Project (No. B310).

\section{References}

1. P. M. Institute, "A Guide to the project management body of knowledge," Proj. Manag. J. vol. 40(2), pp. 104-104, June 2009.

2. J. H. Payne, "Management of multiple simultaneous projects: a state-of-the-art review," Int. J. Proj. Manag. vol. 13(3), 1995, pp. 163-168.

3. M. Martinsuo and P. Hoverfalt, "Change program management: toward a capability for managing valueoriented, integrated multi-project change in its context," Int. J. Proj. Manag. vol. 36(1), 2018, pp. 134-146.

4. Z. Shehu and A. Akintoye, "Major challenges to the successful implementation and practice of programme management in the construction environment: A critical analysis," Int. J. Proj. Manag. vol. 28(1), 2010, pp. 26-39.

5. M. Lycett, A. Rassau and J. Danson, "Programme management: a critical review" Int. J. Proj. Manag. vol. 22(4), 2004, pp. 289-299.

6. D. Partington, S. Pellegrinelli, M. Young, "Attributes and levels of programme management competence: an interpretive study," Int. J. Proj. Manag. vol. 23(2), 2005, pp. 87-95.

7. J. Geraldi, H, Maylor and T. Williams, "Now, let's make it really complex (complicated): a systematic review of the complexities of projects," Int. J. Oper. Prod. Manage. vol. 31(9), 2015, pp. 966 - 990.

8. S. Boccaletti, V. Latora, Y. Moreno, M. Chavez and D. U. Hwang, "Complex networks: structure and dynamics" Complex Systems and Complexity Science. vol. 424(4-5), 2006, pp. 175-308.

9. H. A. Zaabi and H. Bashir, "Analyzing interdependencies in a project portfolio using social network analysis metrics," International Conference on Industrial Engineering and Applications (ICIEA), Singapore, 2018, pp. 490-494.

10. P. B. Pardis, R. B. Austin and J. M. de la Garza, "Network Analysis of Flash-Track Practices" J. Manage. Eng, vol. 33(1), 2016, pp. 04016024.

11. R. Albert and A. L. Barabasi, "Statistical mechanics of complex networks," Rev. Mod. Phys. vol. 74(1), pp. 47-97, June 2001.

12. M. E. J. Newman, "The structure and function of complex networks” SIAM Rev. vol. 45, pp. 167-256, March 2003. 